\title{
Is the Medium Distorting the Message? How the News Media Communicates Advances in Medical Research to the Public
}

\author{
Brent M McGrath, Ronak K Kapadia \\ Class of 2010, Faculty of Medicine, Dalhousie University
}

\section{Abstract}

Among the medically lay public, the news media is one of the primary sources for information on current trends and research findings in health prevention, promotion and treatment. Research suggests that more than $75 \%$ of people act on such information, with a large number of individuals acting solely based on news media reports, with little or no expert consultation. This highlights the influential role of the lay press in issues of population health. However, it has often been noted that information regarding methodology, study limitations financial support, conflicts of interest, and absolute results are often excluded in news media reports on medical issues. A non-systematic review of studies employing content analysis to assess the quality of medical reporting was conducted. The review highlights a variety of common deficiencies in healthcare reporting. The authors make specific recommendations to both scientists and members of the news media to improve healthcare reporting in areas where evidence of deficiencies exist.

\section{Introduction}

Believe nothing you see in the newspapers - they have done more to create dissatisfaction than all other agencies. If you see anything in them that you know is true, begin to doubt it at once.

$\mathrm{T}$ hese words, spoken by Sir William Osler over a century ago, ${ }^{1}$ likely still hold meaning for many physicians and scientists today. In fact, there is recent evidence supporting this lack of trust between scientists and the news media. ${ }^{2,3}$ But is this lack of trust justified? There is no denying the news media's potential for influence on the health attitudes and behaviours of the general public. Whether it is through radio, newspapers, television or the Internet, the role of the media can potentially range from leading to reflecting to at times ignoring the public's interests. In particular, research has shown that the news media not only influences the public's health and medical knowledge, but it also shapes their priorities and behaviours..$^{4-10}$ The news media has even been shown to be a source of information on new research for the scientific and medical community, ${ }^{11}$ as well as for policy makers. ${ }^{12-15}$

Among individuals with neoplastic disease in Canada, it has been found that almost all (86\%) want as much information as possible, and although $83 \%$ cited physicians as their primarily information source, $54 \%$ reported that the amount of information received from their physician or health care provider is insufficient. ${ }^{16}$ Thus, it is not surprising that research has found that the news media is among the public's primary source for information on current trends and advances in biotechnology, health prevention, promotion and treatment. ${ }^{17-20}$ American data has shown that $55 \%$ of people trust the news media to tell them the truth, ${ }^{4}$ and more than $75 \%$ of people report acting on information garnered from said medium. ${ }^{21,22}$ In addition, although greater than $50 \%$ of people have reported discussing health information gained from news media reports with their physician, ${ }^{21,22}$ this suggests that a large number of individuals may act solely based on the news media reports themselves, with little or no expert consultation. To demonstrate this point, investigators found a temporal association between the number of colonoscopies performed and the airing of Katie Couric's discussion of colon cancer screening on her network morning news show. There was between a $17 \%$ and $27 \%$ increase (depending on geographical region assessed) in the number of colonoscopies carried out in the nine months after the broadcast. ${ }^{23}$ Interestingly, the same study did not find a similar increasing trend in the number of mammography and prostate specific antigen tests conducted, which suggests that this increase in colonoscopies was due to the media's report and not a general increase in cancer screening. ${ }^{23}$ Thus, it appears that not only is a significant portion of the public's knowledge regarding disease and treatment gained from the news media, but the media also influences their health behaviour, often without guidance from physicians. This, combined with the fact that an increasing number of Canadians lack a primary care physician,${ }^{24}$ highlights the influential role of the media in issues of individual and population health.

Canadian physicians are aware of this influence, with $84 \%$ reporting that they believe the news media influences the types of treatment that their patients request. ${ }^{25}$ Physicians also indicate concern that patients may have difficulty interpreting the relevance and importance of medical information reported by the news media. ${ }^{16}$ It has been found that while the public may have an interest in interpreting 
medical statistics, as well as a perceived confidence in doing so, neither of these factors implies that they have the ability to do so. ${ }^{26}$ Therefore, health information that is not communicated clearly and accurately may have a great propensity to mislead the public. There is good news for physicians; $80 \%$ of people have indicated that they have not read, seen or heard a news report that led them to question their physician's advice. ${ }^{22}$ Moreover, only $6.2 \%$ of patients and $9.2 \%$ of physicians state that the news media has negatively affected the patient-doctor relationship. ${ }^{16}$

The aim of this paper is to review the literature on the news media's role in communicating new findings in medical research and treatment to the general public. Where available, evidence will be presented on how the news media has performed in this task, where deficits exist and how improvements can be made. The authors will also provide commentary on ways in which this important exchange and translation of information can be made more effective and accurate.

\section{Literature Search}

A literature search was conducted using the database Medline/PubMed. The search covered all years of Medline/ PubMed to 2008. Only those articles printed in English were considered for review. Given the audience, the review will primarily focus on research done in North America. The keywords used were 'medicine', 'medical research', 'media', 'journalism', 'health journalism', 'news', 'newspapers', 'television', 'public health', 'medication' and 'treatment'. Relevant articles were chosen on the basis of their titles and abstracts. Relevance was determined by the authors, based on whether the articles evaluated the effectiveness or accuracy of the media's reporting of current findings in medicine and scientific research. The references of the individual articles were also consulted in an effort to capture any articles missed in the primary literature search.

\section{Medical Journalism}

News has been defined as anything that interests a large part of the community and has never been brought to its attention before. ${ }^{27}$ According to Johnson, ${ }^{19}$ the fundamental question in medical journalism is how best to identify, process and report medical information to the general public. However, in the era of network and cable news offering twenty-four hour coverage of world events, and where science and medical stories have to compete with those in other domains - including economics and politics - it is not surprising that inaccuracies occur in reporting. As a result, journalists have often been charged with being inaccurate, misleading, incomplete, superficial, dramatic and sensationalistic when it comes to reporting on matters of science and medicine..$^{28,29}$
There has also been criticism from within the ranks of journalism. ${ }^{30-32}$ This may not be surprising considering that $77 \%$ of journalists-at-large acknowledge a general lack of understanding regarding the nature of science, such as the tentativeness of most scientific discovery and the complexity of results. ${ }^{33}$ Moreover, in the same study, $62 \%$ of journalists indicated that most members of the news media rarely get the technical details about science and technology correct. ${ }^{33}$ This is consistent with reports of scientists' own perceptions of the media. ${ }^{33}$ In a survey of journalists' own appraisal of their ability to report health care news, $83 \%$ indicated that they had neither received formal training in covering health topics nor in interpreting health statistics, but $73 \%$ stated that such training would be helpful. ${ }^{32}$ Interestingly, although most had received no training, a similar percentage (75\%) of journalists in the study indicated having at least moderate confidence in their ability to report health news, with younger respondents reporting a greater perceived ability. ${ }^{32}$ In all, only $31 \%$ of the journalists surveyed felt very confident in interpreting health news, with only $10 \%$ expressing confidence in interpreting statistics. ${ }^{32}$

\section{Content Analysis}

This paper will focus on the print and television news media. Although the Internet is clearly a vast source of medical information of variable quality, ${ }^{34-36}$ it is beyond the intended scope of the present paper. Similarly, although the public may be exposed to as much as 16 hours of prescription drug advertisements on television each year, ${ }^{37}$ direct-toconsumer advertisements for health related products will not be reviewed. The majority of studies that have evaluated the news media's coverage of advances in medicine have utilized a qualitative research approach known as content analysis. Content analysis is a research tool used to determine the presence of certain words or concepts within texts or sets of texts. Investigators quantify (through coding) and analyze the presence, meanings and relationships of such words and concepts, then make inferences about the messages within the texts, the writer and even the audience. While this is the standard approach in this type of research, it is not without limitations. Some of the most common limitations of this approach include its retrospective nature, sometimes short study time frames, inherent subjectivity, and inability to assess how the public interprets reports. While there is a growing body of evidence to support the notion of a causeeffect relationship between what the news media reports and how the public responds, ${ }^{5-10}$ there is also evidence that does not support such a relationship., ${ }^{4,38,39}$ 


\section{News Media Coverage of Medical Research and Treatment}

One of the earliest of the studies assessing media coverage of medical issues involved an evaluation of the news media's coverage of the benefits and risks of three medications (pravastatin, alendronate, and aspirin). ${ }^{40}$ In this analysis, the authors found that of 207 stories over a four year period, $50 \%$ reported benefits in only relative terms (rather than absolute terms), $47 \%$ mentioned potential adverse effects, $30 \%$ mentioned drug cost, and among the stories that cited an expert, only $39 \%$ mentioned any conflicts of interest. ${ }^{40}$ Reporting relative rather than absolute benefits has the effect of overestimating the magnitude of the findings, thus artificially inflating the public's perception of the benefit of a particular intervention or magnifying their perception of the risks associated with a particular exposure. ${ }^{14}$ Including information about absolute benefits allows the effect of no intervention to be taken into account. ${ }^{41}$ A recent content analysis of the reporting of conflicts of interest in stories about research and medicine over a one-year period found that only $38 \%$ of stories identified the funding agency, only $11 \%$ reported the financial ties of the researchers involved in the study, and only $10 \%$ reported the financial ties of sources quoted in the story. ${ }^{42}$ The authors noted that while financial conflicts of interest were seldom reported in the newspaper stories, much of this information was available to the news media through the specific published scientific article. ${ }^{42}$ Scientists themselves are concerned that their own potential conflicts of interest are not receiving enough coverage. ${ }^{28}$ However, when covered in the news media, focus is often on financial rather than professional or personal conflicts of interest. ${ }^{43}$ Omitting information regarding conflicts of interest ominously threatens to erode the public's trust in the integrity of science and research. ${ }^{43,44}$ Research supports the notion that readers take such conflicts into consideration when appraising the credibility of published medical research. ${ }^{45}$ It is particularly important to know about conflicts of interest because authors with conflicts of interest have been found to be more likely to report positive findings. ${ }^{46}$ In a recent survey of 91 peer-reviewed biomedical journals, $77 \%$ reported collecting information on authors' conflicts of interest, but only $57 \%$ published it. ${ }^{47}$

One study assessed the news media's coverage, over a seven year period, of the National Institutes of Health (NIH) and National Cancer Institute's (NCI) contradictory interpretation of the available evidence on routine mammography screening in women aged 40 to 49 years. The NIH recommendation that no mammographic screening is necessary within this age group was followed within two months by the NCI recommendation that such screening is advisable. ${ }^{41}$ Wells and associates noted that the news media tended to over-represent the support for mammography. ${ }^{41}$
Among these news reports, only about half indicated the benefits, with $95 \%$ of these tending to report benefits in only relative terms. Moreover, $31 \%$ of the news reports did not reference a source..$^{41}$ In a separate study of the same news story, Schwartz and Woloshin ${ }^{48}$ found that over the two weeks following the NIH recommendation to not screen women in this age group, $59 \%$ of the news stories about the $\mathrm{NIH}$ recommendation stated that women should probably or definitely be screened, even though $67 \%$ of all stories indicated that the usefulness of such screening is not certain. Over the two weeks following publication of the NCI recommendation to screen, the level of uncertainty dropped, and $96 \%$ of the news media reports suggested women should be screened. ${ }^{48}$ While the news media appeared to be nearly unanimous, the American College of Physicians continues to be more cautious, recommending that women 40 to 49 years of age be pre-screened, tailoring the decision to screen women on the basis of the women's concerns about mammography and breast cancer, as well as their risk for breast cancer. ${ }^{49}$ The authors also note the difference in tone in the stories covering the two events, with those covering the NIH recommendation expressing a sense of anger, while those covering the NCI reversal were more supportive. The potential reasons for this are intriguing, and may reflect a lack of understanding on the part of the news media of the potential adverse effects of screening and of particular biases in the studies including length bias, lead-time bias and overdiagnosis bias.

A Canadian study analyzing the news media's coverage, over a one-year period, of several recently available prescription drugs found that while the news media tend to mention the benefits, $68 \%$ failed to mention even one adverse effect. $^{50}$ Those that did, all quantified the benefit or harm in relative terms only. Only 3\% of the reports mentioned potential conflicts of interest. ${ }^{50}$ In a recent content analysis of the news media's coverage of the 2002 Canadian healthcare reform debate, the researchers found that episodic coverage (i.e. short term, high volume coverage) was more superficial and positive in nature, while thematic (i.e. extended coverage of the same issue) tended to be more detailed and critical. ${ }^{15}$ Episodic coverage was far more prevalent, implying that this type of coverage had a greater likelihood to impact the public's view of the debate. ${ }^{15}$

In another recent evaluation of the characteristics of health reporting on television news over a one-year period, Pribble and associates ${ }^{51}$ found that $40 \%$ of the broadcasts analyzed reported at least one health story, with $26 \%$ making specific recommendations. Only $38 \%$ of the health stories mentioned medical or scientific research, most doing so superficially, ${ }^{51}$ with only $6 \%$ of stories referencing a specific source. Interestingly, the authors note that two health stories actually reported that exercise may cause cancer. ${ }^{51}$ 
The news media has also been criticized for reporting on preliminary research from scientific meetings. ${ }^{52}$ Woloshin and Schwartz ${ }^{52}$ found that only 3\% of news media reports on preliminary research were about results from human randomized controlled trials. Two-thirds of the studies reported on an intermediate or secondary outcome, with $40 \%$ not quantifying the main result or outcome. ${ }^{52}$ Among those that did report on main results or outcomes, the information was often reported only in relative terms. Study limitations were rarely mentioned, nor was the preliminary nature of the research. Also, only $6 \%$ of media reports about animal research indicated that the results may not apply to humans. ${ }^{52}$ These authors suggest that the news media should not rush to report on preliminary research ${ }^{53}$ and it may in fact benefit the public as well as the research and medical community if they did not report on this type of material at all. It is important to note that only about $44 \%$ of all abstracts ultimately get published. ${ }^{54}$ This rate is not much better (63\%) for randomized controlled trials. ${ }^{54}$ Of all conference abstracts that ultimately get published, $50 \%$ are published within 1-2 years of presentation..$^{54,55-59}$ This implies that the work presented at the original conference is often at least 1-2 years away from being ready for public consumption. More recent work indicates that of those abstracts presented at meetings that ultimately published, only $50 \%$ are published in high-impact factor journals (defined by the study author as a journal with top 10 impact factor rating within its respective specialty area or category). ${ }^{60}$ This breakdown mirrors that of the articles that were prominently featured in news media reports of scientific and medical meetings studied by this group. ${ }^{60}$ And according to the former editor-in-chief of the British Medical Journal, Richard Smith, ${ }^{61}$ only about 5\% of peer-reviewed research that ultimately gets published is credible, the rest is just "rubbish", implying that at best, only a small fraction of the news reports on preliminary research are about research that is of sufficient caliber to be influential at the public level. Smith's is a view supported by others. ${ }^{62,63}$ Thus, it would be difficult to contend that such preliminary work is of any real benefit to the public. Furthermore, there is the potential that if preliminary results from a study affecting public health are reported in the lay press, less attention is given to the results when they are published in their final, peer-reviewed format. ${ }^{64}$ It is the latter that should carry weight in terms of influencing health decisions and perhaps health policy.

\section{Suggestions for Improvement}

It is clear from the review above that important information is being lost in translation - from the medical and research milieu, through the news media filter, to the public. The etiology of this problem is likely complex; however, it has been noted that constraints of time, brevity, and simplicity work antagonistically against efforts toward careful documentation with precautionary qualification. ${ }^{65}$ Accurate communication is compounded by the fact that the scientific audience is often a homogeneous group who view data in a very similar manner, while the news media's audience is much more heterogeneous, bringing different interests, knowledge and experience to the interpretation. As a result, this makes objective, effective and accurate communication, at all levels more challenging. This may be uniquely true for the news media, as they are often left with the task of translating a medical and scientific language into something that the public can understand. Knowing all this, what can be done to improve the nature of medical reporting? To follow are several recommendations aimed at improving medical and research news reporting.

\section{Recommendations for the News Media Industry}

Given the ever-increasing complexities of science and medicine, it would be advisable for those covering this type of news to have specific training, education, and perhaps even certification, in these areas. Members of the news media have themselves noted the differences between reporting general news and reporting medical news, ${ }^{19}$ and a call for specialty training has even come from within. ${ }^{19,32}$ Accuracy is particularly important in topics such as health and medicine, given that those who read it are likely to make important choices based on the information. ${ }^{34}$ At a fundamental level, there needs to be an understanding of medical terminology, physiology, epidemiology, study design, and statistical analysis to keep health news accurate and in the appropriate context. ${ }^{34}$ Schools of journalism, which traditionally offer a single, homogenous curriculum to all students, may wish to begin offering advanced training in specialty areas.

Steps have been made toward this end. In 2002, the NIH Office of Medical Applications of Research (http://medmediacourse.nih.gov) held a symposium entitled "medicine in the media: the challenge of reporting on medical research" in an effort to educate and enhance journalists' abilities in reporting science and medical news. Other professional development workshops include the Association of Health Care Journalists, ${ }^{51,66}$ the Knight Foundation's medical evidence boot camp, and the National Association of Medical Communicators' ${ }^{37}$ educational materials like the Tipsheet. ${ }^{40}$ While these symposia and workshops are a positive and welcomed step, their attendance is voluntary and from the review above, appear not to be sufficient. More formal training may be in order. Even with support, such changes are likely to take time.

There are, however, more immediate remedies to improve the accuracy in reporting. The following recommendations are relatively simple ways to improve the quality of reporting that focus on areas where evidence of a deficiency exists. 
When reporting on issues in medicine and research, the media should keep the following points in mind:

(1) When reporting on treatment or screening studies, always present the results in absolute (rather than relative) terms..$^{34,40,41,53,68}$

(2) Report primary rather than secondary outcomes from clinical trials. ${ }^{34}$

(3) Report the research studies design (i.e. animal research, clinical studies, case reports, case series, case-control studies, controlled cohort studies, or randomized controlled trials) and quantifying how the design affects the studies conclusions. ${ }^{34,41,52,69}$

(4) Avoid making general statements based on single anecdotes. ${ }^{69}$

(5) Avoid reporting on preliminary research presented at scientific meetings as it has been shown that peer review and formal publication improve both the completeness and the accuracy of scientific articles..$^{68,70}$

(6) Examine and report the weaknesses and limitations of research studies..$^{53,68,69}$

(7) Report any conflicts of interest, particularly financial, of interviewed sources as well as the study authors; ${ }^{34,40,41}$

(8) Avoid using only a single source, particularly where controversy exists such as in the NIH and NCI mammography recommendations. . $^{10,34,40}$

(9) Utilize expert sources in addition to, or in place of, the original study authors or spokesperson. ${ }^{34,40}$

(10) State how the current research fits in with prior work. . $^{53,69}$

(11) Report not only benefits, but also possible adverse effects. $^{40}$

(12) In reports on new treatments, indicate the target patient group. ${ }^{40}$

(13) Question findings about a treatment's effects, and represent risks appropriately. ${ }^{69}$

(14) Report on treatment alternatives of newly available medication if they exist, commenting on how the new treatment differs from previous treatments. ${ }^{53}$

(15) If available, provide information of the cost of new treatments relative to existing ones, in the context of effectiveness. ${ }^{34}$

(16) Avoid using vague or sensational terms such as "cure", "miracle", "breakthrough", "promising", "dramatic", "hope", and "victim". ${ }^{34}$

(17) When reporting on new disease testing or screening protocols, mention issues like lead-time bias, length bias and overdiagnosis bias.

(18) Cover science and medicine thematically, not just episodically. ${ }^{10}$

\section{Recommendations for the Medical and Research Establishment}

While many in research and medicine may hold that much of the blame for poor reporting lies solely with the news media, ${ }^{33}$ this is counter-productive. Besides being aware of the recommendations above, there are several areas within the research and medical establishment that evidence shows can be improved upon as well. The following recommendations are relatively simple ways to improve interaction with the press and to ensure that those in the medical establishment, including physicians, researchers and the editors of medical journals are doing all they can to improve accuracy in medical and research news reporting. When dealing with the news media, attempt to keep the following points in mind:

(1) Physicians and scientists must keep apprised of the most current clinical treatment recommendations and avoid holding a persistently favourable stance toward contradicted interventions when newer and stronger evidence emerges refuting these earlier claims. ${ }^{71}$

(2) Physicians should view every patient encounter as an opportunity for health education. This may offset or set straight any incorrect information the patient may have garnered from other sources, including the news media. Education should not be relegated to placement of pamphlets in the waiting room, as this approach is of questionable effectiveness. ${ }^{72}$

(3) When describing their own research findings, researchers should be sure to describe the methods used and the limitations of such an approach. ${ }^{73,74}$

(4) If asked to comment on their preliminary research, researchers should ensure that the preliminary nature of the work is understood, indicating the need to interpret results with caution and the importance of waiting for their work to undergo scientific peer review. ${ }^{52}$

(5) Researchers should openly disclose pertinent conflicts of interest, particularly in industry sponsored studies, both to the journal to which the manuscript is submitted, as well as during interviews with the news media. ${ }^{75,76}$

(6) When asked to comment on recent research findings, expert sources should be aware of the facts, thus, avoiding confusion. ${ }^{29}$

(7) Press releases by medical journals and academic institutions should be presented on the basis of perceived importance,${ }^{77}$ and the study authors should review and edit press releases for accuracy. ${ }^{34}$

(8) Press releases highlighting the latest research should, at a minimum, include information on the studies design, hypothesis, primary outcomes in absolute terms ${ }^{52}$ study limitations and any conflicts of interest.

(9) Organizers of scientific meetings and conferences should avoid issuing press releases on preliminary 
research, unless the evidence to be presented has been appropriately peer reviewed.

(10) The intended goal of a press release should be in the communication of content, rather than the generation of a large amount of news media coverage. ${ }^{48}$

(11) Press releases should list the latest research findings in descending order based on perceived importance as order of presentation has been shown to influence the degree of coverage specific research will receive from the news media. ${ }^{77}$

(12) When appropriate, researchers should maintain a dialogue with the news media regarding updates or changes in previously reported recommendations. ${ }^{10,14}$

\section{Conclusion}

By its own invention, scientific and medical research takes - or perhaps more accurately - demands time. To the researcher, most results are tentative and preliminary, only to become reliable - and thus newsworthy - once replicated and endorsed by colleagues. ${ }^{78}$ Discoveries are adapted and changed through the "thought collective" of researchers over extended time periods. ${ }^{79}$

On the contrary, time is the news media's enemy. The news media is pressured to publish tomorrow's news today. When the media gets it right, people and patients can benefit, but when they get it wrong, patients can be exposed to inaccurate, or worse, harmful information. Moreover, patients may forgo existing effective treatments in the hopes of a new miracle treatment or cure.

From the review above, it is clear that to date the medium has often distorted the message in its reporting of the latest advances in medical research and treatment to the public. With that said, the news media has an enormous potential to have a more positive influence. ${ }^{79,80}$ Physicians, researchers, journalists and the public have been shown to be in strong agreement with respect to what they view as important content in science and medical reporting. ${ }^{81}$ Somehow, this content gets altered on its way into and through the media machinery. It is time to re-calibrate this machine in an effort to increase its reporting precision.

\section{REFERENCES}

1. Bean WB Ed. Sir William Osler: Aphorisms from his bedside teachings and writings. Henry Schuman, New York, 1950.

2. Ransohoff DF, Ransohoff RM. Sensationalism in the media: When scientists and journalists may be complicit collaborators. Eff Clin Pract 2001;4:185-188.

3. Geller G, Bernhardt BA, Gardner M, Rodgers J, Holtzman NA. Scientists' and science writers' experiences reporting genetic discoveries: Toward an ethic of trust in science journalism. Genet Med 2005;7:198-205.

4. Ten Eyck TA. The media and public opinion on genetics and biotechnology: Mirrors, windows, or walls? Public Underst Sci 2005;14:305-316.

5. Wright WR. Mass media as sources of medical information. J Commun 1975;25:171-173.

6. Wallack L, Dorfman L. Television news, hegemony, and health. Am J Public
Health 1992;82:125-126.

7. de Walle HF, van der Pal KM, de Jong-van den Berg LT, Jeeninga W, Schouten JS, de Rover CM, Buitendijk SE, Cornel MC. Effect of mass media campaign to reduce socioeconomic differences in women's awareness and behaviour concerning use of folic acid: Cross sectional study. BMJ 1999;319:291-292.

8. Brodie M, Hamel EC, Altman DE, Blendon RJ, Benson JM. Health news and the American public, 1996-2002. J Health Polit Policy Law 2003;28:927-950.

9. Sharma V, Dowd MD, Swanson DS, Slaughter AJ, Simon SD. Influence of the news media on diagnostic testing in the emergency department. Arch Pediatr Adolesc Med 2003;157:257-260.

10. Benelli E. The role of the media in steering public opinion on healthcare issues. Health Policy 2003;63:179-186.

11. Phillips D, Kanter E, Bednarczyk B, Tastad P. Importance of the lay press in the transmission of medical knowledge to the scientific community. N Engl J Med 1991;325:1180-1183.

12. Jordan DL. Newspaper effects on policy preferences. Public Opin Q 1993;57:191-204.

13. Nisbet MC, Lewenstein BV. Biotechnology and the American media: The policy process and the elite press, 1970 to 1999 . Sci Commun 2002;24:359391.

14. Wilson K, Code C, Dornan C, Ahmad N, Hebert P, Graham I. The reporting of theoretical health risks by the media: Canadian newspaper reporting of the potential blood transmission of Creutzfeldt-Jakob disease. BMC Public Health 2004;4:epub.

15. Collins PA, Abelson J, Pyman H, Lavis JN. Are we expecting too much from print medial? An analysis of newspaper coverage of the 2002 Canadian healthcare reform debate. Soc Sci Med 2006;63:89-102.

16. Chen X, Siu LL. Impact of the medial and the internet on oncology: Survey of cancer patients and oncologists in Canada. J Clin Oncol 2001;19:4291-4297.

17. Freed GL, Katz SL, Clark SJ. Safety of vaccinations: Miss America, the media, and public health. JAMA 1996;276:1869-1872.

18. Cohn V. Vaccines and risks: The responsibility of the media, scientists, and clinicians. JAMA 1996;276:1917-1918.

19. Johnson T. Shattuck lecture - Medicine and the media. N Eng J Med 1998;339:87-92.

20. Larson RJ, Woloshin S, Schwartz LM, Welch HG. Celebrity endorsements of cancer screening. J Natl Cancer Inst 2005;97:693-695.

21. The National Health Council Report: 21 st century house call: The link between medicine and the media. National Health Council, Washington. 1997a.

22. The National Health Council Report: Americans talk about science and medical news. National Health Council, Washington. 1997b.

23. Cram P, Fendrick AM, Inadomi J, Cowen ME, Carpenter D, Vijan S. The impact of a celebrity promotional campaign on the use of colon cancer screening: The Katie Couric effect. Arch Intern Med 2003;163:1601-1605.

24. Esmail N. Canada's physician shortage: Effects, projections, and solutions. The Fraser Institute 2006.

25. Gregg A, Kelly C, Sullivan M, Woolstencroft T. A report on the attitudes of Canadian physicians regarding media coverage of health issues. Toronto: The Strategic Councel, Inc. 1999.

26. Woloshin S, Schwartz LM, Welch HG. Patients and medical statistics: Interest, confidence and ability. J Gen Intern Med 2005;20:996-1000.

27. Bloom SG. The legend of the potholes: Newsroom changes increase medical and health news coverage. Pharos 1996;59:2-7.

28. Shuchman M, Wilkes MS. Medical scientists and health news reporting: A case of miscommunication. Ann Intern Med 1997;126:976-982.

29. Greenland P, Lloyd-Jones D. Critical lessons from the ENHANCE trial. JAMA 2008;299:953-955.

30. Ward B. Environmental reporters: Their own worst critics. Safety and Health 1993; 148:33.

31. Saari MA, Gibson C, Osler A. Endangered species - science writers in the Canadian daily press. Pub Underst Sci 1998;7:61-81.

32. Voss M. Checking the pulse: Midwestern reporters' opinions on their ability to report health care news. Am J Public Health 2002;92:1158-1160.

33. Hartz J, Chappell R. Worlds apart - how the distance between science and journalism threatens america's future. First Amendment Center. Freedom Forum, Arlington, VA. 1997.

34. Silberg WM, Lundberg GD, Musacchio RA. Assessing, controlling, and assuring the quality of medical information on the Internet: Caveant lector et viewor - Let the reader and viewer beware. JAMA 1997;277:1244-1245.

35. Hoffman-Goetz L, Clarke JN. Quality of breast cancer sites on the World Wide Web. Can J Public Health 2000;91:281-284.

36. Ahmad F, Hudak PL, Bercovitz K, Hollenberg E, Levinson W. Are physicians ready for patients with Internet-based health information? J Med Internet Res 2006;8:e22. 
37. Frosch DL, Krueger PM, Hornik RC, Cronholm PF, Barg FK. Creating demand for prescription drugs: A content analysis of television direct-to-consumer advertising. Ann Fam Med 2007;5:6-13.

38. Gamson WA, Croteau D, Hoynes W, Sasson T. Media images and the social construction of reality. Ann Rev Sociol 1992;18:373-393.

39. Radford T. Influence and power of the media. Lancet 1996;347:1533-1535.

40. Moynihan R, Bero L, Ross-Degnan D, Henry D, Lee K, Watkins J, Mah C, Soumerai SB. Coverage by the news media of the benefits and risks of medications. N Engl J Med 2000;342:1645-1650.

41. Wells J, Marshall P, Crawley B, Dickersin K. Newspaper reporting of screening mammography. Ann Intern Med 2001;135:1029-1037.

42. Cook DM, Boyd EA, Grossman C, Bero LA. Reporting science and conflicts of interest in the lay press. PLoS ONE 2007;2:e1266.

43. McComas KA, Simone LM. Media coverage of conflicts of interest in science. Sci Commun 2003;24:395-419.

44. Cohen JJ. Trust us to make a difference: Ensuring public confidence in the integrity of clinical research. Acad Med 2001;76:209-214.

45. Chaudhry S, Schroter S, Smith R, Morris J. Does declaration of competing interests affect readers' perceptions? A randomized trial. BMJ 2002;325:13911392.

46. Friedman LS, Richter ED. Relationship between conflict of interest and research results. J Gen Intern Med 2004;19:51-56.

47. Cooper RJ, Gupta M, Wilkes MS, Hoffman JR. Conflict of interest disclosure policies and practices in peer-reviewed biomedical journals. J Gen Intern Med 2006;21:1248-1252.

48. Schwartz LM, Woloshin S. News media coverage of screening mammography for women in their $40 \mathrm{~s}$ and tamoxifen for primary prevention of breast cancer. JAMA 2002;287:3136-3142.

49. Qaseem A, Snow V, Sherif K, Aronson M, Weiss KB, Owens DK. Screening mammography for women 40 to 49 years of age: A clinical practice guideline from the American College of Physicians. Ann Intern Med 2007;146:511-515.

50. Cassels A, Hughes MA, Cole C, Mintzes B, Lexchin J, McCormack JP. Drugs in the news: An analysis of Canadian newspaper coverage of new prescription drugs. CMAJ 2003;168:1133-1137.

51. Pribble JM, Goldstein KM, Fowler EF, Greenberg MJ, Noel SK, Howell JD. Medical news for the public to use? What's on local TV news. Am J Manag Care 2006;12:170-176.

52. Woloshin S, Schwartz LM. Media reporting on research presented at scientific meetings: More caution needed. MJA 2006a; 184:576-580.

53. Woloshin S, Schwartz LM. What's the rush? The dissemination and adoption of preliminary research results. J Natl Cancer Inst 2006b;98:372-373.

54. Scherer RW, Langenberg P, von Elm E. Full publication of results initially presented in abstracts. Cochrane Database Syst Rev 2007;18:MR000005.

55. Bydder SA, Joseph DJ, Spry NA. Publication rates of abstracts presented at annual scientific meetings: how does the Royal Australian and New Zealand College of Radiologists compare?. Australas Radiol 2004;48:25-28.

56. Stolk P, Egberts AC, Leufkens HG. Fate of abstracts presented at five International Conferences on Pharmacoepidemiology (ICPE): 1995-1999. Pharmacoepidemiol. Drug Safety 2002;11:105-111.

57. Walby A, Kelly AM, Georgakas C. Abstract to publication ratio for papers presented at scientific meetings: how does emergency medicine compare? Emerg Med 2001;13:460-464.

58. Marx WF, Cloft HJ, Do HM, Kallmes DF. The fate of neuroradiologic abstracts presented at national meetings in 1993: rate of subsequent publication in peerreviewed, indexed journals. Am J Neuroradiol 1999;20:1173-1177.

59. Larian B, Namazie A, Agha N, Azizzadeh B, Blackwell K, Wang MB. Publication rate of abstracts presented at the annual meeting of the American Academy of Otolaryngology-Head and Neck Surgery. Otolaryngol. Head Neck Surg 2001;125:166-169.

60. Schwartz LM, Woloshin S, Baczek L. Media coverage of scientific meetings: Too much, too soon? JAMA 2002;287:2859-2863.

61. Smith R. Promoting research into peer review. BMJ 1994;309:143-144.

62. Williamson JW, Goldschmidt PG, Colton T. The quality of medical literature: An analysis of validation assessments. In: Bailar JC, Mosteller F. Medical uses of statistics. Waltham, Mass: NEJM Books 1986. Pp. 370-391.

63. Altman DG. The scandal of poor medical research. BMJ 1994;308:283-284.

64. Girardi E, Petrosillo N, Aloisi MS, Rava L, Ippolito G. Peer-reviewed articles and public health: The mad cow affair in Italian newspapers. JAMA 1998;280:292-294.

65. Nelkin D. An uneasy relationship: The tension between medicine and the media. Lancet 1996;347:1600-1603.

66. Schwitzer G. A statement of principles for health care journalists. Am J Bioeth 2004;4:W9-W13.

67. Schwitzer G, Mudur G, Henry D, Wilson A, Goozner M, Simbra M, Sweet
M, Baverstock KA. What are the roles and responsibilities of the media in disseminating health information? PLoS Med 2005;2:e215.

68. Schwartz LM, Woloshin S. The media matter: A call for straightforward medical reporting. Ann Intern Med 2004;140:226-228.

69. Arnold KM. Medicine and the media: Symposium addresses challenge of reporting on medical research. Sci Editor 2003;26:17-18.

70. Goodman SN, Berlin J, Fletcher SW, Fletcher RH. Manuscript quality before and after peer review and editing at Annals of Internal Medicine. Ann Intern Med 1994;121:11-21.

71. Tatsioni A, Bonitis NG, Ioannidis JPA. Persistence of contradicted claims in the literature. JAMA 2007;298:2517-2526.

72. McGrath BM, Tempier R. Is the waiting room a classroom? Psychiatr Serv 2003;54:1043.

73. Highfield R. Selling science to the public. Science 2000;289:59.

74. Rensberger B. The nature of science. Science 2000;289:61.

75. DeAngelis CD. The influence of money on medical science. JAMA 2006;296:996-998.

76. Fletcher RH, Black B. "Spin" in scientific writing: Scientific mischief and legal jeopardy. Med Law 2007:26:511-525.

77. de Semir V, Ribas C, Revuelta G. Press releases of science journal articles and subsequent newspaper stories on the same topic. JAMA 1998;280:294-295.

78. Jasanoff S. The Fifth Branch: Science Advisors as Policymakers. Harvard University Press, Cambridge, 1994.

79. Young JS. Mass media and medicine: Challenges and opportunities. JAMA 2002;287:772.

80. Shuchman M. Journalists as change agents in medicine and health care. JAMA 2002;287:776.

81. Mountcastle-Shah E, Tambor E, Bernhardt BA, Geller G, Karaliukas R, Rodgers JE, Holtzman NA. Assessing mass media reporting of disease-related genetic discoveries: Development of an instrument and initial findings. Sci Commun 2003;24:458-478.

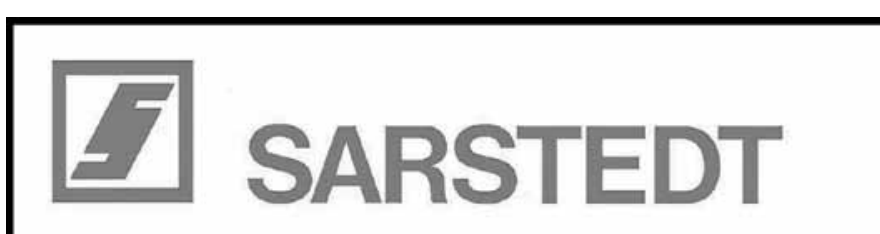

Your partner in medicine and research worldwide

The SARSTEDT Group develops, manufactures and sells equipment and consumables in the field of medicine and research. Ever since it was set up in 1961 the company has continued to grow to the point where it now employs a workforce of 2,500 .
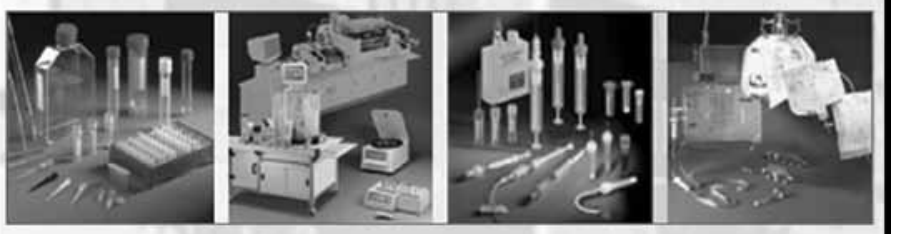

6373 Des grandes prairies Montreal, QC H1P 1 A5

Tel: 1-888-727-7833 Website: www.sarstedt.com 